\title{
Estimation of Travel Time in Urban Streets Using Various Modes
}

\author{
Serin Sara Roy \\ Department of Civil, \\ Muthoot Institute of Technology and Science, \\ Varikoli
}

\author{
Anil R \\ Department of Civil, \\ College of Engineering, Trivandrum
}

\begin{abstract}
Travel time reliability is one of the most understood measures for road users to perceive the current traffic conditions. It helps them to make smart decisions on route choices so as to avoid unnecessary delays. Travel time information to travelers always helps to better manage trips. It helps in making various decisions, such as: route choice, departure time choice etc. and helps to reduce traffic congestion and travel delay. Establishing a relationship between travel times of various modes is always a better solution. The objective of this study is to find out a statistical relationship between public transit and private cars and vice versa. Travel time data of sections of the study routes were collected using GPS and this information was used for representing the present traffic situation. Linear regression models were developed to predict travel times of modes, one with respect to another and travel time measures were validated.
\end{abstract}

\section{Keywords}

Travel time, dwell time, linear regression, GPS.

\section{INTRODUCTION}

Intelligent Transportation Systems (ITS) is a technology which transfers information between systems for improved safety, productivity \& environmental performance. Some of the applications of ITS are Advanced Traveler information systems (ATIS), Advanced Traffic Management Systems, Emergency Management Systems, Commercial Vehicle Operations etc. Out of this ATIS is very important since it well represent the traffic conditions. Travel time information is an indispensable part of traveler information systems. Travel time is one of the most understood measure indices used by transport planners, commuters engineers etc. congestion ,delay and unreliability are the terms that are most associated with present day travel. Faruk et al.[4] . Travel time has been a critical measure used to evaluate the effectiveness of road. This paper will describe how measures of travel time are used in evaluation and better understanding of transportation system. In this study,travel time data of each section of the study route was obtained from GPS and this travel time information was used for representing the present traffic situation. The effect of different types of vehicle on congestion and to assist in formulating rational traffic management measures for urban roads, travel time models were developed. Models were estimated for bus and automobile travel times for different times of a day and traffic compositions, with travel time, dwell time and volume as independent variables

\subsection{Literature Review}

Partha Chakraborthy et al. [1] examined the possibility of using transit vehicle (buses) as probe vehicle for collecting data. They measured the travel time of transit vehicles and automobiles along the same sections on major corridors in Delaware. They developed a procedure that predicts the average travel time of the automobile, based on observed travel time of a bus in the same traffic stream. They compared bus travel time to automobile travel time and suggested a functional form that predicts the automobile travel time as based on the travel time of the bus. SathyaPrabha et al. [6] evaluated the operational efficiency of urban road network using travel time reliability measures. They estimated the measures from average travel time and 95th travel time. They developed travel time models as a function of traffic volume, speed, and distance and validated the travel time measures. Charlie et al. [2] quantified the additional time required by buses due to traffic congestion. The basic approach involved developing a model that estimates bus travel time as a function of overall car travel time. The model was then used to estimate the proportion of bus travel time due to the increase in traffic time over free-flow conditions. They developed a regression model, which estimate the travel time rate of bus.It was expressed as a function of car travel rate, number of passengers boarding per minute, No. of bus stops per mile etc. This model was used to estimate the bus travel time rate, if cars were travelling under free flow conditions and the results were compared with observed bus travel times. Faruk et al. [4] provided a comprehensive review of the current usage of GPS data in transportation planning applications and present a practical integrated methodology for using a robust source of GPS data, for commercial vehicle travel time prediction. They collected truck GPS data and taxi GPS data. A comparison with observed truck travel times collected from a limited source of truck-GPS data reveals that travel times obtained from taxi-GPS data approximate those of trucks, and can be used to supplement truckGPS travel time data on a wider scale.

\subsection{Objectives}

The objectives of the study are

- To develop a model that estimate Bus travel time as a function of car travel time

- To develop a model that estimate Car travel time as a function of bus travel time

- To verify the model by the data collected 


\section{STUDY AREA}

The study route selected for the work was an urban stretch (Fig.1 Sreekaryam to East Fort via Kesavadasapuram comprises of approximately $10 \mathrm{~km}$ ) in Thiruvananthapuram city which is the state capital and southern part of Indian subcontinent.

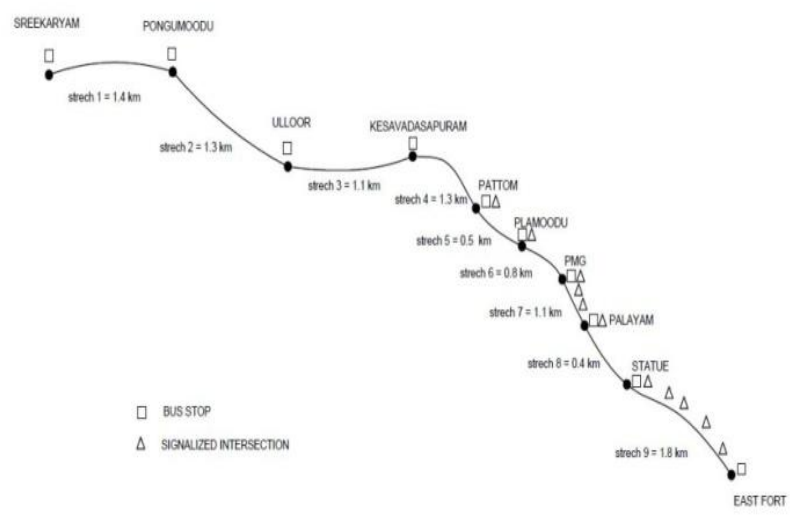

Figure 1: Study route (not in scale)

The study route has been divided in to 9 stretches based on major bus stops or junctions.

\section{METHODOLOGY}

Study route was classified into three segments based on geometric and traffic factors. Survey was done for 19 weekdays. Data collection was carried out using hand held GPS. Data collected are travel time, dwell time and traffic volume. The Map source software was used for extracting data from GPS device. Linear regression analysis was used to develop bus and car models. The models were validated using MAPE (Mean Absolute Percentage Error).

\section{DATA COLLECTION}

The survey was carried out during the morning peak hours. The data consists of 19 days travel time data of all modes of vehicles like public transit, two wheelers, three wheelers and four wheelers. The secondary data was used for identifying the parameters which influences the travel time prediction. After identifying the parameters, data was collected by using handheld GPS and traffic volume was collected by taking videos at each segment of the study routes during the morning peak hours. The Map source software was used for extracting data from GPS device. The logged data includes time of arrival and departure, position, length, speed of travel etc. Secondary data includes the road inventory data was collected from NATPAC (Transportation Research Centre) Trivandrum.

\section{DATA ANALYSIS}

From the data, time taken by each vehicle to travel through the study route was calculated. In order to incorporate parameters like geometric factors, traffic factors, dwell time etc., logical segmentation of the study route was necessary. Some of the factors that influence route segmentation are Geometric factors, Traffic Factors etc. Based on these factors and road inventory data from NATPAC, the study route was classified into three stretches as shown in the table 1 given.

Table1: Characteristics of the study Stretches

\begin{tabular}{|c|c|c|c|}
\hline Parameters & $\begin{array}{l}\text { segment1 } \\
\text { Sreekaryam } \\
\text { - } \\
\text { Kesavadasa } \\
\text { puram }\end{array}$ & $\begin{array}{l}\text { Kesavadasap } \\
\text { uram- } \\
\text { Palayam }\end{array}$ & $\begin{array}{l}\text { segment } \\
3 \\
\text { Palayam } \\
- \\
\text { Eastfort }\end{array}$ \\
\hline $\begin{array}{l}\text { Length of } \\
\text { the route }\end{array}$ & $3.8 \mathrm{Km}$ & $4.4 \mathrm{Km}$ & $3.2 \mathrm{Km}$ \\
\hline $\begin{array}{l}\text { Width of the } \\
\text { road }\end{array}$ & $7 \mathrm{~m}$ & $14 \mathrm{~m}$ & $14 \mathrm{~m}$ \\
\hline $\begin{array}{l}\text { No. of } \\
\text { Lanes }\end{array}$ & $\begin{array}{l}2 \text { lane ( } \\
\text { undivided) }\end{array}$ & $\begin{array}{l}4 \text { lane } \\
\text { (divided) }\end{array}$ & $\begin{array}{l}4 \text { lane } \\
\text { (divided) }\end{array}$ \\
\hline Type of road & NH 47 & MG road & MG road \\
\hline Land Use & $\begin{array}{l}\text { Commercial } \\
\text { /Residential }\end{array}$ & $\begin{array}{l}\text { Commercial/ } \\
\text { Public }\end{array}$ & Mixed \\
\hline $\begin{array}{l}\text { Shoulder } \\
\text { Type }\end{array}$ & $\begin{array}{l}\text { Earthen } \\
\text { shoulder }\end{array}$ & $\begin{array}{l}\text { Footpaths on } \\
\text { both sides }\end{array}$ & $\begin{array}{l}\text { Footpath } \\
\text { s on both } \\
\text { sides }\end{array}$ \\
\hline $\begin{array}{l}\text { Traffic } \\
\text { volume }\end{array}$ & $3964 \mathrm{veh} / \mathrm{hr}$ & $4400 \mathrm{veh} / \mathrm{hr}$ & $\begin{array}{c}6412 \mathrm{veh} / \mathrm{h} \\
\mathrm{r}\end{array}$ \\
\hline Parking & $\begin{array}{l}\text { No separate } \\
\text { parking lots }\end{array}$ & $\begin{array}{l}\text { On street } \\
\text { parking/off } \\
\text { street parking } \\
\text { facilities }\end{array}$ & $\begin{array}{l}\text { On street } \\
\text { parking }\end{array}$ \\
\hline $\begin{array}{l}\text { No. of bus } \\
\text { stops }\end{array}$ & 4 & 5 & 4 \\
\hline
\end{tabular}

\subsection{Model development}

The linear relationship between travel time(dependent variable) and the influencing factors (independent variables) was computed by using the multiple linear regression equation. Linear regression is one of the most widely studied and applied statistical and econometric techniques. $\mathrm{R}^{2}$ is used to account for the changes in the degrees of freedom. This approach is a general and flexible approach for testing the statistical difference between competing models.

\subsubsection{Bus Travel Time Model}

A Linear regression model was developed using SPSS (Statistical Package for the Social Sciences) software. Bus travel time (BTT) was taken as dependent variable. Application of bus travel time model is to predict the bus travel time with the help of other independent parameters. Some of the important parameters which affect bus travel time are car travel time, dwell time and volume of traffic etc. Bus travel time can be expressed as function of car travel time, dwell time and volume. But here, dwell time was avoided in modeling bus travel time because, the assumption is that in future all vehicles(car) will be equipped with GPS there by car travel time can be easily determined. Traffic volume is another independent parameter which can also be determined easily. But the effect of dwell time of bus is not considered since we are modelling bus travel time as a function of car travel time. 


\section{Sreekaryam - Kesavadasapuram}

$\mathrm{BTT}=1.391+0.878($ Car travel time $)+0.277($ volume $)$

\section{Kesavadasapuram - Palayam}

$\mathrm{BTT}=2.484+0.257($ car travel time $)+0.760($ volume $)$

\section{Palayam - Eastfort}

$\mathrm{BTT}=2.849+0.835($ Car travel time $)+0.023$ (volume $)$

\subsubsection{Car Travel Time Model}

Car travel time models are used for predicting car travel time as a function of bus travel time. Car travel time (CTT) was taken as dependent variable and Bus travel time, Dwell time of the bus and volume were taken as independent variables. Government of Kerala is equipping all KSRTC buses with GPS units as part of strengthening the Kerala State Road Transport Corporation. Once this is implemented the bus travel time and dwell time of the buses can be easily determined. By knowing the traffic volume the car travel time can be expressed as a function of these parameters. Correlation matrix obtained for car as well as bus was same and found out that all parameters are moderately correlated to each other. The table below shows the results of parameter estimation of the model.

Table2: Model Parameter estimates (Kesavadasapuram- Palayam)

\begin{tabular}{llll}
\hline \multirow{4}{*}{ Kesavadasapuram - Palayam } \\
Model & Variables & $\beta$ & t-statistic \\
\hline Bus & Constant & 2.484 & 1.154 \\
& Car travel time & 0.257 & 1.790 \\
& volume & 0.760 & 3.707 \\
& $\mathrm{R}^{2}$ & 0.642 & \\
Car & t-table & 1.734 & \\
& Constant & 0.636 & 0.267 \\
& Bus travel time & 0.232 & 1.904 \\
& Dwell time & 2.238 & 2.942 \\
& Volume & 0.046 & 1.757 \\
& $\mathrm{R}^{2}$ & 0.586 & \\
& t-table & 1.734 & \\
\hline
\end{tabular}

Models developed are shown below.

\section{Sreekaryam - Kesavadasapuram}

$\mathrm{CTT}=1.225+0.263(\mathrm{BTT})+1.030($ Dwelltime $)+0.131$ (volume)

\author{
Kesavadasapuram - Palayam \\ $\mathrm{CTT}=0.636+0.232(\mathrm{BTT})+2.238($ Dwelltime $)+0.046($ volume $)$
}

\section{Palayam-Eastfort}

$\mathrm{CTT}=0.386+0.272(\mathrm{BTT})+0.293$ (Dwelltime) +0.080 (volume)

Table 3: Model parameter estimates( Sreekaryam kesavadasapuram

\begin{tabular}{llll}
\hline \multirow{4}{*}{ Mreekaryam - Kesavadasapuram } \\
Bus & Variables & $\beta$ & t-statistic \\
\cline { 2 - 3 } & Constant & 1.391 & 0.748 \\
& Car travel time & 0.878 & 3.015 \\
& volume & 0.277 & 1.751 \\
& $\mathrm{R}^{2}$ & 0.725 & \\
& t-table & 1.734 & \\
Car & Constant & 1.225 & 1.046 \\
& Bus travel time & 0.263 & 1.735 \\
& Dwell time & 1.030 & 1.833 \\
& Volume & 0.131 & 1.943 \\
& R & 0.788 & \\
& t-table & 1.734 & \\
& & & \\
\hline
\end{tabular}

Table 4: Model parameter estimates Palayam-Eastfort)

\begin{tabular}{llll}
\hline \multirow{4}{*}{ Model } & \multicolumn{3}{c}{ Palayam- Eastfort } \\
& Variables & $\beta$ & t-statistic \\
\hline Bus & Constant & 2.849 & 2.466 \\
& Car travel time & 0.835 & 2.733 \\
& volume & 0.023 & 0.495 \\
& $\mathrm{R}^{2}$ & 0.585 & \\
Car & t-table & 1.734 & \\
& Constant & 0.386 & 0.391 \\
& Bus travel time & 0.272 & 1.534 \\
& Dwell time & 0.293 & 1.766 \\
& Volume & 0.080 & 2.780 \\
& $\mathrm{R}^{2}$ & 0.722 & \\
& t-table & 1.734 & \\
\hline
\end{tabular}

\subsection{Model Validation}

Mean Absolute Percentage Error was used to validate the developed models. It is defined as the percentage of the absolute difference between the field data and the predicted data. MAPE is given by 


$$
\text { MAPE }=\frac{1}{n} \sum \frac{/ \text { fielddata-simulateddata } /}{\text { fielddata }} \times 100
$$

$\mathrm{n}=$ Number of samples

MAPE value of

$$
\begin{aligned}
& 0-10 \%=\text { Very Good } \\
& 10-20 \%=\text { Good } \\
& 20-30 \%=\text { Satisfactory }
\end{aligned}
$$

Bus travel time and car travel time were taken for another 5 days for the same stretch. Developed models were validated by using this data .MAPE obtained for three stretches are shown below. MAPE values of all the stretches are found to be in between 0 and 20 and the models were found to be good.

Table 5: MAPE of the three stretches

\begin{tabular}{llll}
\hline MODES & \multicolumn{3}{l}{ MAPE } \\
\hline & $\begin{array}{l}\text { Sreekaryam } \\
\text { Kesavadasapu } \\
\text { ram }\end{array}$ & $\begin{array}{l}\text { Kesavadasap } \\
\text { uram } \\
\text { Palayam }\end{array}$ & $\begin{array}{l}\text { Palaya } \\
\text { m- } \\
\text { Eastfor } \\
\text { t }\end{array}$ \\
\hline BUS & 5.69 & 5.93 & 11.52 \\
CAR & 6.87 & 7.49 & 3.97 \\
\hline
\end{tabular}

Another way to assess the effectiveness of the model is by visual assessment of predicted and actual travel times. Figure displays below shows the actual and predicted average travel times for both models for three stretches. It was evident from the graphs that estimated model was effective in predicting the travel times on the selected road.

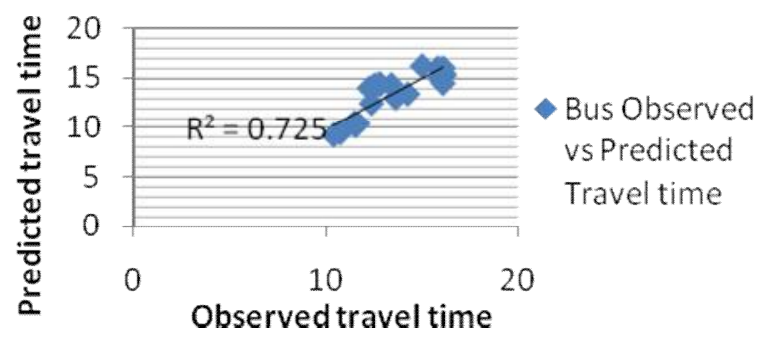

Figure 1:Variation of bus travel time(Sreekaryamkesavadasapuram

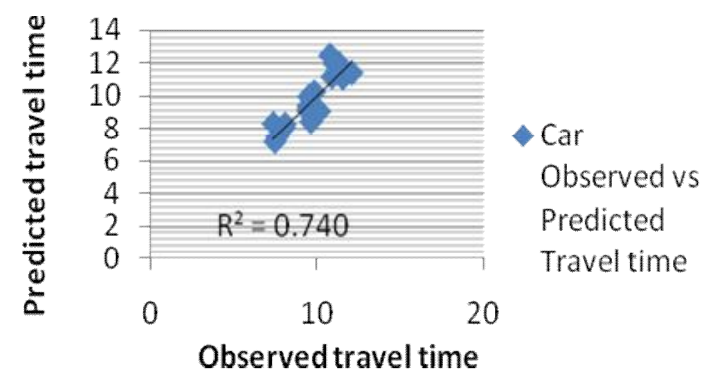

Figure 2: Variation of Car travel time(Sreekaryamkesavadasapuram

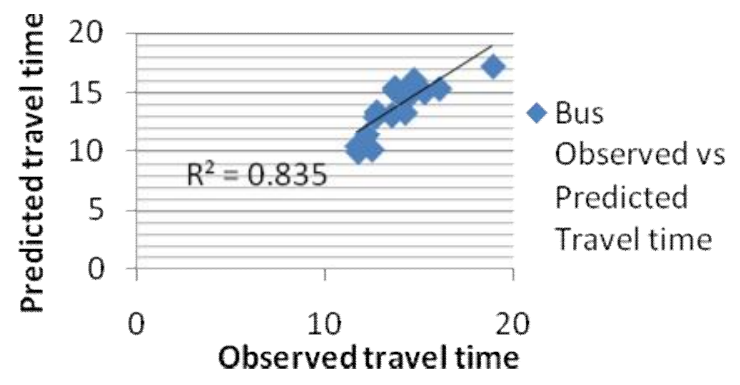

Figure 3: Variation of Bus travel time (kesavadasapuramPalayam)

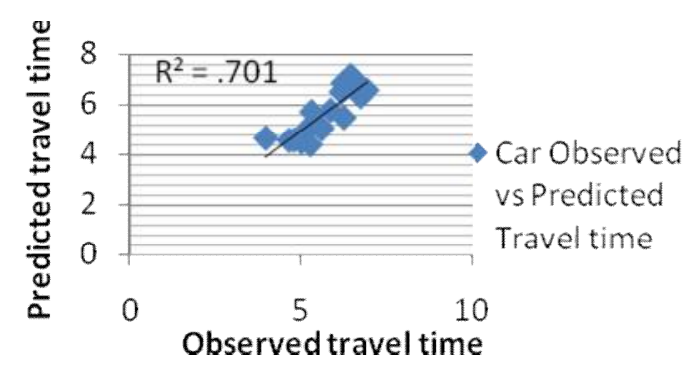

Figure 4: Variation of Car travel time (kesavadasapuramPalayam)

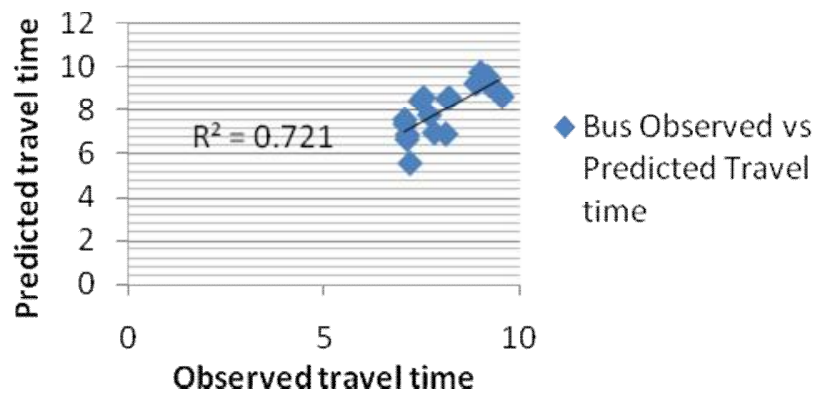

Figure 5: Variation of Bus travel time (Palayam- Eastfort) 


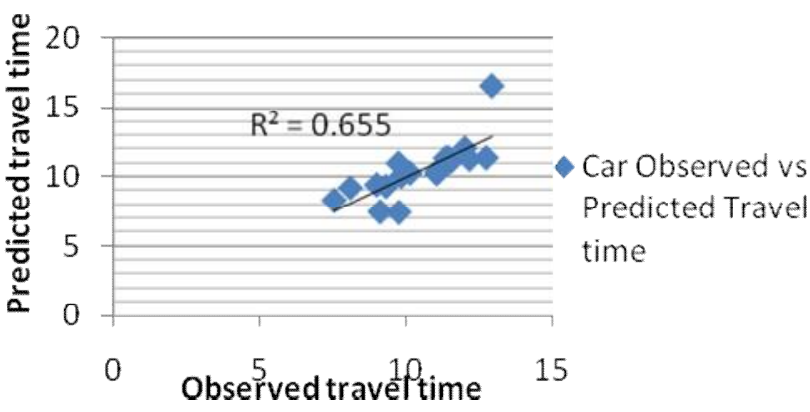

Figure 6: Variation of Car travel time (Palayam- Eastfort)

\section{SUMMARY \& CONCLUSION}

A travel time survey was conducted and travel time taken by Public vehicles and Private cars along each link in the study stretch was estimated. Segmentation of the study route was done based on traffic factors, geometric factors and road inventory data obtained from NATPAC. Bus travel time and car travel time for three stretches were modeled using SPSS. Independent variables that included in the model were average travel time, dwell time and volume. Linear regression analysis yielded reasonable parameter estimates for three stretches. In the models, volume and dwell time gives a positive effect to travel time of vehicles. Volume and dwell time have an additional impact on flow. Increase in volume obviously causes an increase in travel time during peak hour. $\mathbf{R}^{2}$ Statistics for all the stretches were found to be relevant and tstatistics for all parameters were found to be significant. Most of the $\mathrm{t}$ - Statistics are found to be more than that of $\mathrm{t}$ - value obtained from t- tables. $\mathbf{R}^{2}$ value for Sreekaryam - kesavadasapuram stretch was found to be more compared to other stretches. From the models it was found out that, Bus travel time depends on car travel time and volume. For all three stretches, it was found out that car travel time depends on bus travel time, volume of traffic, and dwell time. Validation of travel time models was carried out using statistical method. MAPE (Mean Absolute Percentage Error)was the statistical measure used to test the model performance .MAPE values of all the stretches were found to be in between 0 and 20 and model was proved as fit to find future variation in travel time of vehicles. Effectiveness of the models was assessed by visual assessment of predicted and actual travel times.It was evident from the graphs that estimated models are also effective at predicting the travel time on the selected stretches.

\section{REFERENCES}

[1] Chakroborty.P., Kikuchi S ;(2004)"Using Bus Travel Time Data to Estimate Travel Times on Urban Corridors". Journal of the Transportation Research Board, No. 1870, TRB, National Research Council, Washington, D.C., 2004, pp. 18-25

[2] Charlie. E., Mcknight ., Herbert .S.(2004)" Impact of traffic congestion on bus travel time in Northern New Jersey" Transportation Research Record Journal of the Transportation Research Board. No 1884, TRB, National Research Council, Washington, D C ,2004, pp. 27-35
[3] Chung E., Bhaskar A., (2012) "Benefits and issues of bus travel time estimation and Prediction "Australasian Transport Research Forum 2011 Proceedings 26 - 28 September 2012, Perth, Australia

[4] Faruk E., Ozbay k.,( 2013) "Commercial Vehicle Travel Time Estimation in Urban Networks using GPS Data from Multiple Sources" Paper Submitted for Presentation and Publication at the Transportation Research Board's 92nd Annual Meeting, Washington, D.C., 2013

[5] Kho.S., Rae Cho .j.,(2001)"Estimating Average Ravel Time From Bus Travel Times" Proceedings of the Eastern Asia Society for Transportation Studies, Vol.3, No.2, October 2001

[6] Prabha S., Mathew S.,(2013) "Evaluation of operational efficiency of urban road network using travel time reliability measures" International Journal Of Research In Engineering And Technology, November 2013 